DOI: http://dx.doi.org/10.22484/2177-5788.2017v43n2p261-275

\title{
Agência experimental e produção de conhecimento em Jornalismo
}

\author{
Andrea Sanhudo Torres \\ Pedro L. Goergen
}

Resumo: Este artigo se propõe a refletir sobre a relevância da Agência Experimental de Jornalismo (AgênciaJor), da Universidade de Sorocaba (Uniso), enquanto espaço laboratorial para as práticas jornalísticas e de ações cooperadas que envolvem teoria-técnica-prática, essenciais à apreensão do conhecimento com base na formação humanista. O texto apresenta a estrutura e a organização da agência, que atua na capacitação profissional, desenvolvendo a percepção crítica da produção dos meios de comunicação e da função social do jornalista, bem como a interação com a sociedade, parceiros e comunidade acadêmica. Aborda ainda a participação dos estudantes e dos professores-orientadores, envolvidos no desenvolvimento das atividades propostas, bem como as práticas pedagógicas aplicadas que visam além da relação ensino/aprendizagem e ampliam a formação ética e cidadã a partir da produção de conhecimento.

Palavras-chave: Jornalismo. Agência Experimental. Ensino. Conhecimento. Prática jornalística.

\section{Experimental Agency and knowledge production in Journalism}

Abstract: This article proposes to reflect on the relevance of the Experimental Journalism Agency (AgênciaJor), University of Sorocaba (Uniso), as laboratory space for journalistic practices and cooperative actions that involve theory-technique-practice, essential to the knowledge acquisition based on humanistic formation. The text presents the structure and organization of the agency, which acts in the professional training, developing the critical perception of the production of the media and the social function of the journalist, as well as the interaction with society, partners and academic community. It also addresses the participation of students and guiding teachers, who are involved in the development of the proposed activities, as well as applied pedagogical practices that aim beyond the teaching/learning relationship and extend the ethical and citizen formation from the production of knowledge.

Keywords: Journalism. Experimental Agency. Teaching. Knowledge. Journalistic practic. 


\section{Introdução}

As universidades têm refletido historicamente o quadro social de sua época e incorporado em suas agendas a temática fornecida pela sociedade onde se encontram inseridas. Dessa forma, o debate sobre as funções da universidade, frente à expansão de modelos globalizados de educação superior, permeia a integração entre ensino-pesquisa-extensão quanto à formação integral dos estudantes e às exigências mercadológicas.

Nesse contexto, a educação superior se vê frente às reformas do mercado de trabalho, à precariedade do emprego e às novas exigências de modalidades educativas e profissionais, determinadas pelo capitalismo global. Como descreve Ibañez (2006), a imposição de um sistema educacional a uma hipervalorizada especialização, vem impedindo a percepção de uma visão global e essencial - humanista - do saber e do próprio mundo. Em relação às práticas de ensino nas universidades, da graduação até a pós-graduação, um dos dilemas mais discutidos, conforme Costa (2002), diz respeito à aparente contraposição entre a abordagem humanista e a visão pragmática do ensino, numa relação dicotômica para a produção de conhecimento.

Entendemos, assim, que as ciências humanas e a filosofia são saberes humanos, e não devem ser dissociadas da técnica, valorada exclusivamente enquanto prática profissional independente da problemática humana geral. As questões relativas à divisão entre humanidades e técnicas, dentro das instituições de educação superior, tendem a ser resolvidas por sistemas classificatórios das funções de ensino. Ao se classificar em graus de importância algumas funções da universidade em detrimento de outras funções, corre-se o risco de instaurar e legitimar as disputas internas numa instituição que deve estar no melhor equilíbrio possível para atender a sociedade, a qual deve ser o seu fim.

Mas se a função das áreas das humanidades tornar-se apenas o de apontar o "bom" e "verdadeiro", pode acabar assumindo um papel de simples apêndice da tendência à exclusividade tecnológica na formação dos cidadãos. Isso acaba por apresentar uma contradição fundamental quando se espera que uma instrução superior contribua também com o processo de melhoria do ser humano. No entanto, o "processo que não pode ser interrompido" nas universidades atuais serve de alerta para que as humanidades, enquanto ciências, não tenham que encontrar seus papéis específicos ou um "espaço" determinados pelas práticas. Mas que perpassem todas as práticas, na busca de realizar a sua natureza que é melhorar o ser humano.

Ortega y Gasset (1999, p. 60), já na década de 1930, quando escreveu os artigos que compõem Missão da Universidade, afirma que o desenvolvimento das ciências humanas nas 
universidades aparecia como "resíduo", aplicação de um pouco de "cultura geral" aos universitários, "em que não se compreende por que está aí”.

Nesse sentido, Goergen (2006) aponta que o compromisso social da universidade deve versar sobre seu sentido emancipador para a sociedade como um todo, caso omissa, correrá o risco de se colocar a serviço dos interesses hegemônicos do sistema neoliberal. Dessa forma, o ensino de jornalismo na graduação, em um cenário constante de mudanças, frente às funções da universidade quanto ao ensino, à extensão e à pesquisa, se dá a partir de ações multidisciplinares e interdisciplinares, pois articulam duas ou mais disciplinas no processo de busca do conhecimento.

A formação do profissional em jornalismo vem enfrentando inúmeros desafios nas últimas duas décadas devido, principalmente, às transformações no mercado de trabalho a partir das inovações tecnológicas. Atualmente, são mais de 300 cursos de Jornalismo no Brasil que buscam atender a um fazer jornalístico em expectativa pela sociedade, oferecendo ao mercado um profissional que contemple suas exigências: multiqualificado.

A determinação do Supremo Tribunal Federal ${ }^{1}$ (STF), em 2009, pela inconstitucionalidade da exigência do diploma para o desenvolvimento das atividades jornalísticas não aliviou a responsabilidade das Instituições de Educação Superior (IES) na formação dos jornalistas. O relatórioº elaborado pela Comissão de Especialistas, instituída pelo Ministério da Educação, com as novas diretrizes Curriculares Nacionais para o Curso de Jornalismo, aponta que:

\begin{abstract}
As iniciativas recomendadas para a melhoria dos cursos de graduação, no contexto das novas regras para o exercício profissional, correspondem aos anseios das entidades sindicais e acadêmicas, defensoras do ensino de qualidade, e ganham legitimidade com as declarações explícitas das empresas do ramo, assegurando que, mesmo sem a obrigatoriedade do diploma, continuarão a contratar os graduados em jornalismo que tenham competência profissional. (BRASIL, 2009, p. 3).
\end{abstract}

Nesse sentindo, a Agência Experimental em Jornalismo (AgênciaJor), implantada em 2010, pelo curso de Jornalismo da Universidade de Sorocaba (Uniso), vem oferecendo aos estudantes de jornalismo, condições para que desenvolvam plenamente os conhecimentos científicos, técnicos e éticos. Atende ainda às Diretrizes Curriculares Nacionais, publicadas pelo Conselho Nacional de Educação, através da Resolução nº 1, de 27 de setembro de 2013. Em

\footnotetext{
${ }^{1}$ Cf. Recurso Extraordinário 511.961, apresentado pelo relator Gilmar Mendes. Disponível em: <http://redir.stf.jus.br/paginadorpub/paginador.jsp?docTP=AC\&docID=605643>. Acesso em: 20 out. 2017.

${ }^{2}$ Cf. Relatório da Comissão de Especialistas. Disponível em: <http://portal.mec.gov.br/dmdocuments/ documento_final_cursos_jornalismo.pdf>. Acesso em: 20 out.2017
} 
2012, a AgênciaJor, além de núcleo de produção jornalística integrado ao curso, passa a compor os projetos de extensão da universidade. Para Martins (2014, p. 10):

\begin{abstract}
Ao institucionalizar a agência numa linha extensionista, reforça-se o tripé universitário (ensino-pesquisa-extensão), que articula a produção de conhecimento necessária à formação profissional com a prática discente, além da aproximação entre a universidade e a sociedade, beneficiada, direta ou indiretamente, com o trabalho desenvolvido junto às instituições, afinal elas detêm informações de interesse público.
\end{abstract}

Ao associar ensino e extensão, a AgênciaJor passa a incrementar a pesquisa na graduação, como importante laboratório para o desenvolvimento do Trabalho de Conclusão de Curso - monografia e dos Projetos Experimentais-Produto, que têm por orientação demandas temáticas regionais. Objetiva-se, dessa forma, atender à universidade, mantendo nos valores humanos uma dimensão fundamental, e por obrigação a formação de cidadãos críticos; além de oferecer aos estudantes algo mais que um diploma e habilidades profissionais. Para Dias (2005a), não é pouco o que se espera da educação superior, pois, além das demandas clássicas, dos compromissos com o aprofundamento dos valores humanísticos, surgem as novas exigências ligadas à globalização e às consequências do acelerado desenvolvimento tecnológico e informacional.

\footnotetext{
Apesar de todas as crises e dificuldades, não se pode negar que a universidade tem sido historicamente, dentre as instituições sociais, uma das principais, talvez mesmo a mais importante para a preservação e o aprofundamento do humanismo e seus valores no mundo ocidental. A universidade desde séculos vem consolidando o humanismo pela produção rica, rigorosa e crítica, nas áreas das ciências, artes, das práticas sociais da vida em geral. (DIAS, 2005a, p. 102).
}

Nesse cenário, o conhecimento tem sido amplamente reconhecido como o principal insumo da economia. Dias (2005a) alerta ainda que conhecimento não se consome como matéria-prima, ao contrário se amplia, se enriquece, se multiplica ao ser incorporado ao acervo individual e social, transmitidos de uma pessoa a outra e ao ser aplicado. Nesse sentido, entendemos que as ações educacionais que proporcionam o aprendizado e a apreensão do conhecimento, com base humanista, levam, também, ao desenvolvimento de habilidades e valores essenciais para a prática do jornalismo e a vida em sociedade. 


\section{Agência Experimental de Jornalismo}

A Agência Experimental de Jornalismo (AgênciaJor), como um núcleo do curso de Jornalismo da Universidade de Sorocaba, apresenta-se estruturada para o desenvolvimento de uma proposta didática e pedagógica para a formação de profissionais do jornalismo. Ao mesmo tempo em que compõem um espaço laboratorial para as práticas jornalísticas, a Agênciajor também está inserida na matriz curricular do curso de Jornalismo enquanto componente curricular, numa preparação para os estudantes na experimentação de novas possibilidades e discussões que envolvam os processos de mudanças nas redações e na regulamentação profissional. Bem como, possa exercer a missão da universidade em ações comunitárias, já que a Universidade de Sorocaba se constitui por ser uma instituição comunitária e laica.

No espaço laboratorial interdisciplinar, composto por uma redação jornalística, na qual os estudantes desenvolvem atividades nos campos do jornalismo impresso, digital, rádio, TV, fotografia, projeto gráfico e assessoria de imprensa, possibilita à viabilização e à produção de projetos de ensino, de pesquisa e de extensão universitária. A AgênciaJor mantém o formato de prestadora de serviço, com a finalidade de experimentação das práticas profissionais, buscando atender à excelência acadêmica e ao VI Eixo de prática laboratorial, determinado pela Resolução $n^{\circ} 1$, de 27 de setembro de 2013.

VI - Eixo de prática laboratorial, que tem por objetivo adquirir conhecimentos e
desenvolver habilidades inerentes à profissão a partir da aplicação de informações e
valores. Possui a função de integrar os demais eixos, alicerçado em projetos editoriais
definidos e orientados a públicos reais, com publicação efetiva e periodicidade
regular, tais como: jornal, revista e livro, jornal mural, radiojornal, telejornal,
webjornal, agência de notícias, assessoria de imprensa, entre outros. (BRASIL, 2013,
p. 5).

Assim, a implantação da Agência Experimental de Jornalismo, com a oportunidade de parcerias com os meios de comunicação locais e regionais, contempla efetivamente o Projeto Político Pedagógico do Curso de Jornalismo quanto da contribuição e do comprometimento da Universidade de Sorocaba com o desenvolvimento social e de cidadania nos contextos regionais.

Aos estudantes, a AgênciaJor proporciona à inserção, já nos primeiros períodos do curso, na prática jornalística e no mercado de trabalho que irão enfrentar, podendo ainda cumprir com a carga horária obrigatória destinada às atividades complementares e estágio. Apresenta como missão a formação científico-técnico-prático, baseada na ética e na construção 
do pensamento crítico, tornado o estudante em um profissional preparado para o ambiente e os desafios da atividade jornalística.

Em conjunto com o curso de Jornalismo, implantado em 1995, pela Universidade de Sorocaba, a AgênciaJor vem contribuindo para a manutenção do curso como referência na formação de profissionais, inserindo cerca de $70 \%$ dos egressos no mercado dos meios de comunicação, instituições e empresas.

As atividades da Agência Experimental de Jornalismo têm como norteadores os seguintes valores: ética; transparência; senso crítico; cooperação; criatividade; competência profissional; compromisso com seus públicos; liderança; e eficácia. Atendendo ao Projeto Político Pedagógico do curso, a AgênciaJor cumpre com os objetivos de contribuir na capacitação das habilidades e competências essenciais à formação profissional do estudante de Jornalismo; atende à demanda por recursos humanos com postura ética e participativa nos setores privado e público, que além de desenvolverem uma visão crítica e analítica, também, respondem às exigências de um mercado competitivo e de uma sociedade em desenvolvimento, através dos programas de ações cooperativas à comunidade acadêmica e sociedade.

\section{Organização da Agência Experimental de Jornalismo}

A Agência Experimental de Jornalismo apresenta-se dividida em seis núcleos: Jornalismo Impresso, Jornalismo Digital, Rádio e TV, Fotografia e Produção Gráfica, Jornalismo Científico e Assessoria de Imprensa e Comunicação Integrada. Com as possibilidades oferecidas pela nova convergência midiática, os núcleos trabalham em conjunto e integrados, em parceria com os Laboratórios de Comunicação da Universidade de Sorocaba (Estúdio de Rádio, Estúdio de TV e ilhas de edição e Estúdio de Fotografia), com o aproveitamento total da produção acadêmica, atendendo à demanda em ensino, pesquisa e extensão. Assim, além do ensino nas práticas jornalísticas, a AgênciaJor propõem a realização de cursos de extensão e a divulgação científica.

a) Jornalismo Impresso - Envolve a produção dos componentes curriculares do curso de Jornalismo com práticas textuais em meios impressos; desenvolve veículos de comunicação impressos, como jornais murais e boletins informativos, além de reportagens de repercussão jornalística; produz e desenvolve reportagens para os veículos parceiros de Sorocaba e região; divulga os Projetos Experimentais - Produto. 
b) Jornalismo Digital - Desenvolve e implanta projetos em mídias digitais, envolvendo as práticas dos componentes curriculares, como Jornalismo Digital, com a criação de blogs para a comunidade acadêmica e divulgação de eventos; divulga os Projetos Experimentais - Produto; alimenta as redes sociais e o blog www.focasnarede.com.br, mantidos pela Agência Experimental de Jornalismo, além dos portais da Uniso e da Rádio Uniso.

c) Rádio e TV - Divulga a produção em Rádio e TV pelos veículos parceiros de Sorocaba e região, com programas próprios, inserções na programação local e divulgação dos Projetos Experimentais - Produto (reportagens e documentários); colabora na produção do programa Rádio Inclusão, em parceria com os Laboratórios de Comunicação da Universidade de Sorocaba e Rádio Cruzeiro FM; colabora na produção de reportagens para a Rádio Uniso.

d) Fotografia e Produção Gráfica- Organiza e mantém o banco de imagens do curso de Jornalismo, de eventos da Instituição e da produção da AgênciaJor; produz material fotográfico e de ilustração para as coberturas jornalísticas; desenvolve projetos gráficos para os meios impressos, bem como para o material de divulgação produzido pelos demais núcleos; produz material exclusivo aos veículos parceiros de Sorocaba e região.

e) Jornalismo Científico - Desenvolve a prática em jornalismo especializado, com o jornalismo científico, na divulgação de pesquisas desenvolvidas pelos programas de pós-graduação da universidade, bem como do programa de Iniciação Científica e Trabalhos de Conclusão de Curso, junto aos veículos parceiros de Sorocaba e região; colabora na organização e cobertura de eventos acadêmicos; incentiva o estudante a participar de encontros de pesquisadores e divulgação científica; apresenta produção científica em congressos, encontros, seminários e outros.

f) Assessoria de Imprensa e Comunicação integrada - Desenvolve projetos em assessoria de imprensa e planejamento estratégico voltados à comunidade acadêmica e sociedade civil organizada; atende ao Terceiro Setor de Sorocaba; organiza eventos; colabora na demanda interna de Comunicação da universidade; desenvolve projetos em comunicação integrada em parceria com a Agência Experimental em Relações Públicas (A.gente) e a Agência Experimental em Publicidade e Propaganda (CRIA), que envolvam questões sociais, culturais e ambientais. 


\section{Estrutura física e material da Agência Experimental de Jornalismo}

A Agência Experimental de Jornalismo funciona em um espaço físico, no Campus Cidade Universitária Professor Aldo Vannucchi, na Universidade de Sorocaba, com 12 computadores com pacote Adobe, acesso à rede e wi-fi, três impressoras multifuncionais, câmeras fotográficas e vídeo, datashow, televisor, um ramal telefônico e armários. Conforme a necessidade da cobertura jornalística, outros equipamentos são solicitados aos Laboratórios de Comunicação, bem como a utilização dos estúdios e ilhas de edição. A AgênciaJor conta ainda com as assinaturas dos principais veículos nacionais, como O Estado de S. Paulo, Folha de S. Paulo e Veja; e locais, Cruzeiro do Sul, Diário de Sorocaba e Ipanema.

\section{Educação, ensino e práticas pedagógicas}

A Agência Experimental de Jornalismo da Uniso vem atuando como uma redação, proporcionando aos estudantes variedade de experiências práticas e oportunidades de exercitar e aprimorar técnicas no cumprimento das tarefas jornalísticas, bem como de terem os conteúdos produzidos por eles veiculados em canais de comunicação próprios ou em veículos da imprensa local e regional.

Desde 2011, a agência conta um bolsista Probex (Projeto de Extensão), e atende a alunos em estagiário obrigatório ou no cumprimento de atividades complementares. Os alunos de Jornalismo estão envolvidos na cobertura de eventos realizados na própria universidade e no desenvolvimento de reportagens com produção e veiculação de conteúdos multimídia. Realizam, ainda, o clipping e o monitoramento do noticiário relacionado à Universidade de Sorocaba nos veículos locais.

O conteúdo é produzido sob a orientação de professores-orientadores e passa por revisão final antes da finalização e veiculação. As revisões e correções são discutidas pelos professores com os alunos envolvidos na tarefa, proporcionando oportunidade de argumentação e ampliando o aprendizado.

A destinação do material não é restrita aos canais de comunicação da própria AgênciaJor ou instituição Além de ser postado no blog www.focasnarede.com.br, mantido pela AgênciaJor, as reportagens, notas, fotos, vídeos são compartilhados em rede social (www.facebook.com/focasnarede), com um alcance médio que ultrapassa três mil pessoas por semana. O material também é oferecido e, havendo interesse, é destinado de forma colaborativa 
à Assessoria de Comunicação Social da Universidade que pode divulgá-lo em seus canais de comunicação ou para a imprensa como release.

De maneira direta, a Agência também destina à imprensa o material jornalístico produzido pelos estudantes da Uniso. Isso ocorre a partir do material produzido pelos estagiários na própria Agência ou com o material produzido regularmente pelos estudantes para os componentes curriculares em qualquer período do curso de Jornalismo. Ao serem identificados pelos professores dos componentes curriculares pela qualidade ou pelo interesse jornalístico para divulgação, os trabalhos realizados em sala de aula podem passar por algum processo de edição para então serem oferecidos aos veículos de comunicação para veiculação. Havendo a publicação, o conteúdo obrigatoriamente é identificado como produção da Agência Experimental de Jornalismo da Uniso.

O jornal Cruzeiro do Sul, que tem circulação regional, tem parceria firmada com a AgênciaJor e recebe regularmente textos como sugestão para publicação. A parceria com o Cruzeiro do Sul rendeu à Agência, em 2015, dois prêmios: $1^{\circ}$ lugar na categoria Estudante e o Prêmio Tim Lopes, como a melhor reportagem do ano em Direitos Humanos $\left(15^{\circ}\right.$ Prêmio Jornalístico ASI/SCHAEFFLER de Direitos Humanos); e em 2016, o $1^{\circ}$ lugar na categoria Estudante, no $16^{\circ}$ Prêmio Jornalístico ASI/SCHAEFFLER de Direitos Humanos. Com a Rádio Cruzeiro FM, a AgênciaJor mantém, em parceria com o LabCom/Uniso, o programa Rádio Inclusão, veiculado diariamente, às $6 \mathrm{~h}$.

Outras atividades que envolvem a Agência de Jornalismo é o apoio na organização e cobertura de eventos, como a Semana do Esquenta (Recepção dos Calouros), Semana Associação Sorocabana de Imprensa- ASI/Jornalismo, Semana de Comunicação e Encontro de Jornalismo e Terceiro Setor. Este último concentra as atividades em Assessoria de Imprensa às instituições do Terceiro Setor de Sorocaba e Região, a um custo estimado em R 1 milhão na produção de veículos e serviços, prestados de forma voluntária.

Também desenvolve projetos em comunicação integrada, com a Agência Experimental em Publicidade e Propaganda (CRIA), como a campanha solidária Lacre do Bem, criada em 2016, que consiste na arrecadação de lacres de latas de alumínio para trocar por cadeiras de rodas, numa ação parceria com a CCR ViaOeste. A campanha arrecadou, em 2017, a primeira cadeira de rodas. Em 2017, a AgênciaJor deu início a Campanha Meias do Bem, em parceria com empresa Puket, de São Paulo, que visa à arrecadação de meias para a produção de cobertores, numa iniciativa conjunta com os demais cursos da área da Comunicação e Design. 


\title{
Participação do estudante
}

Para Marques (2013), “a experiência em laboratório assenta-se nos conceitos de educação vista como ato conjunto de condução e criação, e de ensino, que sinaliza para uma apreensão do aluno a partir da prática". Dessa forma, as atividades laboratoriais desenvolvidas na AgênciaJor vão além da repetição mecânica e tecnicista de rotinas de redação, ou mesmo da mera reprodução de práticas jornalísticas.

\begin{abstract}
O profissional, portanto, não é aquele que apenas executa sua profissão, mas sobretudo quem sabe pensar e refazer sua profissão. Está incluída a especialização operativa, mas sobretudo o que chamamos de formação básica. Esta depende mais que tudo da propedêutica, resumida no questionamento reconstrutivo. Ao lado disso, alimenta-se também da multidisciplinaridade, que não passa da aplicação mais coerente do aprender a aprender: a especialidade isolada desaprende, não só porque reduz a realidade ao que dela imagina saber, mas igualmente porque, ao não comunicar-se, perde a noção do conhecimento como desafio e obra comum. (DEMO, 2005 apud MARQUES, 2013, p. 34).
\end{abstract}

Conforme Pereira et al. (2014, p. 4), a capacidade de experimentar, proporcionada aos estudantes, contribui como "exercício para o desenvolvimento de sujeitos que ultrapassem a simples relação ensino/aprendizagem, ampliando sua formação crítica e de autonomia”. Além disso, essa formação leva o estudante a "ações de intervenção em sua realidade de forma a tornarem-se comunicadores comprometidos com o desenvolvimento político-social de suas cidades e regiões".

Nesse sentido, a Agência Experimental em Jornalismo, enquanto espaço laboratorial, oferece aos estudantes a complementaridade ao aprendizado de sala de aula, bem como a interação multidisciplinar e interdisciplinar, não apenas em conhecimento, como entre os demais estudantes e professores.

Para Marques (2013, p. 34), todo o "projeto pedagógico, principalmente em laboratório, envolve valores como os do trabalho em equipe e do papel do professor em sala de aula". Prática que leva o estudante a buscar soluções aos problemas, identificar oportunidades, perceber desafios e compreender o mundo. Esse trabalho propõe a interação, o diálogo, o comprometimento, a responsabilidade, a compreensão, a pontualidade e diversos outros aspectos que compõem um grupo que produz em equipe.

A AgênciaJor atende, anualmente, alunos do primeiro ao oitavo períodos. O tempo médio de permanência do estudante na AgênciaJor é de seis meses, tempo que o capacita para as vagas de estágio. Em sete anos de existência, o setor já recebeu oito bolsistas de extensão, 
que ao término das atividades, em dois semestres, são encaminhados a estágios em meios impressos locais, emissoras de rádio e TV, além de portais online.

O grupo de estudantes atendidos pela AgênciaJor consegue, ao final da experiência adquirida, apresentar um portfólio com a sua produção, satisfatório para a contratação pelas empresas locais e regionais. Por outro lado, as empresas contratantes acompanham a produção da AgênciaJor através das ações desenvolvidas, como campanhas em comunicação, premiações e mesmo veiculando o material desenvolvido pelos estudantes. A relação da AgênciaJor com os empregadores se dá ainda através dos professores-orientadores, que mantêm um relacionamento estreito e contatos semanais com as redações parceiras. Dessa forma, os empregadores têm conhecimento das práticas pedagógicas desenvolvidas junto aos estudantes, que levam à reflexão, à postura ética e à postura estratégica na solução de problemas e desafios da rotina jornalística.

Outra demanda importante ao Projeto Político Pedagógico do curso de Jornalismo é a realização do Trabalho de Conclusão de Curso, em forma de monografia, e os Projetos Experimentais, em forma de produtos. Nesses casos, a AgênciaJor tem participação ativa, pois são das experiências nas práticas laboratoriais desenvolvidas ao longo do curso, associadas à formação base centrada nas humanidades, que nascem as propostas para os projetos de pesquisa e a realização dos projetos experimentais.

\footnotetext{
A integração das atividades científicas e docentes será conseguida desde que o docente tenha em mente que toda investigação universitária deve ser explorada como fonte de ensino e treinamento e que nenhum investigador deve esquivar-se do exercício do ensino. O pesquisador que ensina leva para a sala de aula o inconformismo e a incerteza que conduzem o jovem a perceber, no conhecimento incompleto, a forma de lidar com o desconhecido e de questionar o que se supõe conhecido. (COSTA, 2002, p. 507).
}

\section{Participação do professor-orientador}

Os professores-orientadores que atuam na Agência Experimental de Jornalismo são indicados pela coordenação do curso, conforme o perfil profissional e formação acadêmica. $\mathrm{O}$ docente deve estar ciente do perfil dos estudantes de jornalismo da Universidade de Sorocaba e da realidade que os cerca, a fim de estabelecer compromissos com a missão da instituição, o Projeto Político Pedagógico do curso de Jornalismo e com a formação integral dos estudantes.

Segundo Tondato (2010, p. 116), o corpo docente das instituições de educação superior vê um jovem bombardeado por informações, acostumado à segmentação, habituado à rapidez, mas também em formação, inseguro e ansioso. Isso faz com que as funções dos professores 
sejam ainda mais importantes em relação às práticas pedagógicas, capazes de reconhecer as necessidades dos estudantes, por sua base histórica, "numa ação constante de comunicação, entendendo que a produção social dos sentidos se dá nas relações sócio históricas da sociedade e que o indivíduo/aluno "está no mundo com o mundo"”.

Tondato (2010, p. 117) alerta que "o professor não é mais o mestre, transmissor de saberes, mas sim orientador, facilitador, que deve ajudar o indivíduo/aluno". Publio e Mader destacam que, no contexto atual, a exigência sobre a docência é ampliada:

[...] além de trabalhar com novas formas de interação, o professor deve planejar de forma meticulosa, acompanhar todo o processo de aprendizagem do aluno, dominar alternativas de produção e disponibilização de materiais, como o hipertexto e hipermídia, incentivar e proporcionar autonomia e manter coesão e integração grupal. (PUBLIO; MADER, 2009, p. 28).

É neste sentido que se insere o desenvolvimento de saberes específicos através das práticas pedagógicas desenvolvidas na Agência Experimental de Jornalismo. Ao professororientador cabe a função de "guia" que deve priorizar o conhecimento, a convivência e a troca, proporcionando um ambiente de aprendizado, considerando ainda a pluralidade de ideias e diversidade de personalidades.

O papel do professor desponta como sendo o facilitador da aprendizagem de seus alunos. Seu papel não é o de ensinar, mas ajudar o aluno a aprender; não é transmitir informações, mas criar condições para que o aluno adquira informações; não apenas fazer brilhantes preleções para divulgar a cultura, mas organizar estratégias para que o aluno conheça cultura existente e crie cultura. (ABREU; MASETTO, 1990, p. 11).

Para tanto, cabe ainda ao professor-orientador a percepção acerca das mudanças tecnológicas, que levam a novos conhecimentos e saberes. As funções do professor-orientador não apenas visam capacitar os estudantes no entendimento do que são e como ocorrem as ações de comunicação, mas como correlacionam conceitos (humanístico, filosófico, jurídicos e éticos) em que se baseiam, bem como aos instrumentos que utilizam nas práticas jornalísticas.

Para Tondato (2010, p. 121), a agência experimental é um espaço privilegiado da realização de muitos ideais pedagógicos e deve ser entendida e mantida como:

Espaço de atividades práticas, realizadas segundo uma dinâmica intensa interação professor-aluno, permitindo a desmitificação do processo ensino-aprendizagem baseado na transmissão professoral do conhecimento; Espaço de experimentação do novo, de reflexão sobre os erros e compreensão dos acertos, num processo constante de avaliação formativa e somativa. 
Dessa forma, apontam Publio e Mader (2009, p. 28), "diferentemente das aulas expositivas tradicionais, a prática das agências experimentais agrega a utilização de uma complexa gama de recursos, mais concernente com as necessidades pedagógicas atuais". Para os autores, o professor perdeu o "status do centralizador da informação", para se constituir "orientador da informação", e "em tempos atuais, a informação está à disposição de todos, e o bom professor certamente estará atento em buscá-la”.

Assim, a tarefa que procuramos atender é a construção de uma ação mediadora, em que o professor-orientador possibilite a apreensão do conhecimento. Estar atento, ouvir todas as partes, entender que o processo de aprendizagem é mais importante que a produção são qualidades essenciais para chegarmos aos melhores resultados.

Nesse processo de aprendizagem, cresce o aluno e cresce o professor. Ambos aprendem e ensinam; desenvolvem um processo de conhecimento que agrega valores a todas as partes envolvidas.

\section{Considerações finais}

Ao pensar a educação superior como um espaço de diálogo, entendemos que as práticas pedagógicas tem a missão de transformar a informação num processo de conhecimento, numa inter-relação de descobertas. Dessa forma, o que a Agência Experimental de Jornalismo busca oferecer, além da contribuição para o crescimento e amadurecimento profissional dos estudantes, é a ampla consciência do sujeito enquanto agente transformador do real através de saberes e fazeres com conhecimento e ética. Nesse processo, o aprendizado tem base no contexto em que o estudante está inserido, numa universidade comunitária e regional. Ao perceber o real, o estudante deve ser capaz de assimilar, refletir, agir e potencializar as relações com a sociedade.

Ao professor-orientador, cabe o papel da mediação, um "guia" nessa nova experiência, com estratégias e práticas pedagógicas multidisciplinares e interdisciplinares, que levem de fato à construção de sujeitos comprometidos com um mundo em constante transformação social, cultural, político e econômico.

No entanto, o caminho para atingir tais objetivos, como o estudante participativo e ativo e o professor-orientador, em seu papel integral, muitos são os obstáculos. Os estudantes ainda mantêm o ideal do profissional técnico, mão de obra especializada para atender às pressões imediatistas emanadas pelo mercado. Quando ingressam na universidade, anseiam pela prática 
isolada dos saberes jornalísticos, corroborados por uma educação básica fragmentada e desconexa com o projeto de uma formação integral humanista.

Por outro lado, os colegiados são compostos por um corpo docente formado por profissionais, problema comum às Instituições de Educação Superior quando se pensa as áreas específicas dos cursos. $\mathrm{O}$ entendimento da função humanística da educação leva tempo para a compreensão, e demanda diálogos e questionamentos em torno de um projeto educacional ampliado e não apenas tecnicista.

Outro desafio a ser superado é o financiamento para os projetos de educação com propostas de abrangência universal, já que a tendência mercadológica caminha em situação oposta, na redução de disciplinas de caráter humanístico. Na contramão da formação integral do estudante, o mercado vem priorizando a formação tecnicista, de rápida duração e o ensino reprodutivo exclusivamente.

Por fim, a proposta da Agência Experimental de Jornalismo, através de um projeto educacional com base humanista, apresenta-se como alternativa à tendência mercadológica reducionista, acreditando que é possível investir esforços numa formação mais condizente com as necessidades humanas do mundo contemporâneo.

Conforme apresenta Dias (2005b), o sentido essencial da responsabilidade social da educação superior está na produção e na socialização de conhecimentos, que sejam importantes para o desenvolvimento econômico que tenha sentido de cidadania pública. $\mathrm{O}$ autor entende que não se deve subjugar a ética à técnica, mas que a produção de conhecimento seja para consolidar a democracia, relevantes para os contextos regional e nacional.

\section{Referências}

ABREU, Maria Celia; MASETTO, Marcos T. O professor universitário em aula. São Paulo: MG Ed. Associados, 1990.

BRASIL. MINISTÉRIO DA EDUCAÇÃO. CONSELHO NACIONAL DE EDUCAÇÃO. Resolução no 1 , de 27 de setembro de 2013. Disponível em:

$<$ http://portal.mec.gov.br/index.php?option=com_docman\&view=Dowloads\&alias=14242rcess0001-13\&Itemid=39192>. Acesso em: 20 out.2017.

BRASIL. MINISTÉRIO DA EDUCAÇÃO. Diretrizes Curriculares Nacionais para o Curso de Jornalismo. Relatório da comissão de especialistas. 2009. Disponível em: $\langle$ http://portal.mec.gov.br/dmdocuments/documento_final_cursos_jornalismo.pdf $>$. Acesso em: 20 out. 2017>. Acesso em: 20 out. 2017.

COSTA, Vital Paulinho. O papel do docente na universidade. Medicina, Ribeirão Preto, 35, out./dez. 2002. Disponível em <http://revista.fmrp.uso.br/2002/ vol35n4/vital\%20paulino.pdf>. Acesso em: 31 jul. 2016 
DIAS SOBRINHO, José. Dilemas da educação superior no mundo globalizado. Sociedade do conhecimento ou economia do conhecimento? SP: Casa do Psicólogo, 2005a.

DIAS SOBRINHO, José. Educação superior, globalização e democratização. Qual universidade? Revista Brasileira de Educação, Rio de Janeiro, n. 28, jan./abr. 2005b. Disponível em: <http://dx.doi.org/10.1590/S1413-24782005000100014 \. Acesso em: 20 out. 2017.

GOERGEN, Pedro L. Universidade e compromisso social. Brasília: INEP, 2006. Coleção Educação Superior em Debate.

IBAÑEZ, José Roig. La educación ante un nuevo ordem mundial. Madrid: Diaz de Santos, 2006.

MARTINS, Juliane. Agência experimental como projeto de extensão universitária. Extensão em Foco, Curitiba, n. 10, jul./dez.2014.

MARQUES, Márcia. Tudo ao mesmo tempo agora: o ensino de jornalismo em cenário permanente de mudanças. In: MORAES JUNIOR, Enio; MALULY, Luciano Victor Barros; OLIVEIRA, Dennis de (Orgs.). Antes de pauta: linhas para pensar o ensino do jornalismo no século XXI, SP: ECA-USP, 2013.

ORTEGA Y GASSET, José. Missão da universidade. Rio de Janeiro: EdUERJ, 1999.

PEREIRA, Fabiana da Costa et al. A Comunicação Integrada na A4 Agência Experimental de Comunicação. In: CONGRESSO DE CIÊNCIAS DA COMUNICAÇÃO NA REGIÃO SUL, 15, 2014, Palhoça (SC). Anais... Disponível em

<http://www.portalintercom.org.br/anais/sul2014/resumos/R40-0662-1.pdf>. Acesso em: 08 ago. 2017.

PUBLIO, Marcelo Abílio; MADER, Maria Paula Mansur. A relevância das agências experimentais na aprendizagem dos alunos de Comunicação Social. Cadernos da Escola de Comunicação, Curitiba, v. 1, n. 7, 2009. Disponível em:

$<$ http://revistas.unibrasil.com.br/cadernoscomunicacao/index.php/comunicacao/article/viewFi le/71/70>. Acesso em: 08 ago. 2017

TONDATO, Márcia Perencin. Projetos experimentais, projetos integrados e agências experimentais: novas práticas pedagógicas no ensino de comunicação. Comunicação \&

Educação, São Paulo, Ano XV, n. 2, maio/ago. 2010.

Andrea Sanhudo Torres - Universidade de Sorocaba - Uniso. Sorocaba | São Paulo | Brasil. Contato: andrea.torres@prof.uniso.br.

Pedro L. Goergen - Universidade de Sorocaba. Uniso. Sorocaba. Sorocaba | São Paulo | Brasil. Contato: pedro.goergen@prof.uniso.br. 